\title{
Ethno-medicinal uses of promising plants in various formulations in cure of ailments in Chhindwara district, Madhya Pradesh
}

\begin{abstract}
Many plants play a vital role in primary health care in lives of rural people as they posses therapeutic properties. The present study had been conducted in Chhindwara district in state of Madhya Pradesh to document ethno medicinal uses of 50 species of plants, comprising of 41 genera and 27 families prevalent in six cluster of villages of tribal communities residing in Batkakhapa, Chhind, Haarai, Junardeo, Patalkot and Rated in cure of ailments such as Leucoderma, sun-stroke, skin burn, skin disease, boils, baldness and hair problems, male and female impotency, leucorrhoea, lactation, heart ailments, blood pressure, diabetes, intestinal worms, scorpion sting, snake -bite, jaundice, fracture and loss of appetite. The tribal community uses various formulations such as, powder, paste, decoction, oil, juice, pulp and raw material etc. of root, bulb, tuber, seed, leaves, fruits of plant species, as being used by local inhabitants based upon local traditions which are vanishing among Bhariya and Gond tribes. This highly valuable knowledge being scattered, secretive, fast eroding prior to vanish needs proper documentation. This continuous erosion of this vital knowledge had renewed the interest and development of medicinal plant sector in India specially the state of Madhya Pradesh which has enormous amount of dense forest. The paper concludes that ethnic communities had vital knowledge on indigenous uses of medicinal plants utilizing various formulations in cure of various ailments.
\end{abstract}

Keywords: indigenous practices, ethno-medicine, formulations, bhariya and gond tribes
Volume 4 Issue 7 - 2016

\author{
Rajiv Rai \\ Scientist F,Tropical Forest Research Institute, India \\ Correspondence: Rajiv Rai, Scientist F,Tropical Forest \\ Research Institute, PO RFRC Jabalpur MP \\ (Indian Council of Forestry Research and Education), Tel 91 \\ 9479644205,Email rai_rajiv_57@hotmail.com
}

Received: October 08, 2016 | Published: December 28, 2016

\section{Introduction}

Man had been associated with plants since the time of his existence. Medicinal plants play an important role on the lives of rural people. Use of plant based drugs in cure of various ailments is as old as human civilization. Since time memorial mankind and his civilization is dependent on plants for food, medicine, fiber. This knowledge of intimate relationship between man and plants around his immediate surrounding has passed on through several hundreds of generations. India is a good source of medicinal plants. The age old traditional interaction of people living in forest and forest fringes with the use of their natural resources available in the surrounding of their habitat, eco-system, environment had developed traditional knowledge on use of forest resources in human welfare activities. ${ }^{1,2}$ Most of these tribal communities who collect various forest produce utilizes them for their own consumption, welfare of the community, as well as income generation for their livelihood. Inspite of the influence of modernization, cultural diffusion, most of the indigenous practices, as adopted by these tribal communities are still endowed with certain belief. $^{2}$

Chhindwara division of Madhya Pradesh is a vast emporium of plant resources and is known to harbor rich thick forest and inhabited by Bhariya and Gond tribal communities. They are mostly dependent on forests for their daily needs. A number of ethnobotanist's had documented use of forest resources, medicinal plants in cure of various ailments in Madhya Pradesh. The ethno-medicinal studies documented and reported in different tribal pockets of Madhya
Pradesh such as plants in traditional medicine as prevalent among indigenous community of Bundelkhand region in Sagar district, ${ }^{3}$ plants used by Kol tribes in Rewa district, ${ }^{4}$ plants used by Baiga and Gond tribes in Mandla district in MP, 5,6 medicinal plants used by Bheel tribes in Guna district, ${ }^{7}$ medicinal plants used by Bheel tribes in Jhabua district, ${ }^{8}$ plants in medicinal use by Gond tribes in Khargone districts, ${ }^{9}$ plants used in cure of various ailments by Bhilala tribes in Alirajpur district, ${ }^{10}$ medicinal plants with indigenous uses by Sahariya tribe in Guna district, ${ }^{11}$ some traditional medicinal plants used by Sahariya and Baiga primitive tribes in Madhya Pradesh, ${ }^{12,13}$ threatened medicinal plants prevalent among Sahariya tribes in Chambal ecoregion, ${ }^{14}$ conservation plan of tribal's for medicinal use in Central India, ${ }^{15}$ some unreported plants used by aboriginals in Betul district, ${ }^{16}$ some indigenous uses of medicinal plants by Bhil tribes in Jhabua district, ${ }^{17}$ management of key medicinal plants by local indigenous communities Gond and Korku tribes in Bori, Pachmarhi sanctuary and in Pachmarhi biospheres, ${ }^{18,19}$ ethnobotanical documentation of plants in promising pockets of primitive tribes in $\mathrm{MP},{ }^{20}$ plants in prevalent in herbal remedies amongst Bhil tribes of Bijagarh in West Nimar. ${ }^{21}$

\section{Material and methods}

\section{Study area}

Ethno- medicinal data was collected during survey conducted in the year 2014-2016 in six clusters of villages namely, Batkakhapa, Chhind, Haarai, Junardeo, Patalkot and Rated in Chhindwara district in state of Madhya Pradesh as shown in Figure 1. These localities are 
spread from $21^{\circ} 28^{\prime}$ to $22^{\circ} 49^{\prime}$ North (latitude) and $78^{\circ} 40^{\prime}$ to $79^{\circ} 24^{\prime}$ East (longitude) and over an area of $11,815 \mathrm{~km}^{2}$ of dense forest in state of Madhya Pradesh. The present investigation was carried out in during period 2014 September to 2016 February. The study was conducted by interviews followed by focus group discussions with local indigenous communities. During the visits a number of traditional herbal healers, elderly person of tribal communities, were contacted and information was collected through interview, observations and discussion held during field survey.

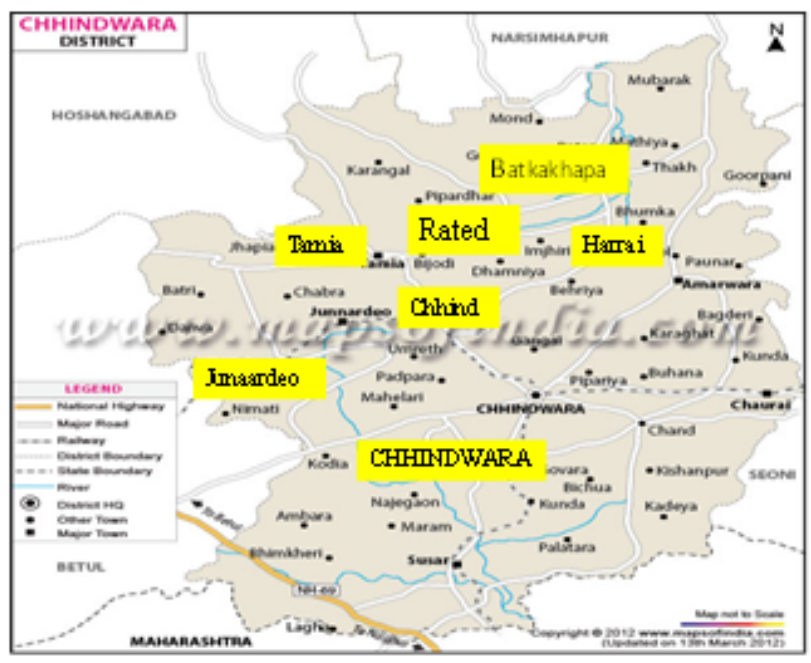

Figure I Map showing clusters suryed in Chhindwara district.

\section{Documentation of medicinal plants}

The information from Local Traditional healers and local community was collected during periodic field survey being carried out in the study area identified based on distribution pattern of ethnic communities having folk knowledge. The local vaidraj or traditional healers and people inhabitants in as observed during survey conducted were in use of medicinal plants growing around their habitat in vicinity of forests. These medicinal plants were collected from wild. The local traditional herbal healers (vaids) had specialized knowledge about availability of these plants (trees, shrubs, herbs, and climbers) as well as their seasonal availability, time of collection and collected roots, leaves, seeds and fruits in cure of various ailments and prepared herbal formulations for use as shown in Figure 2-4.

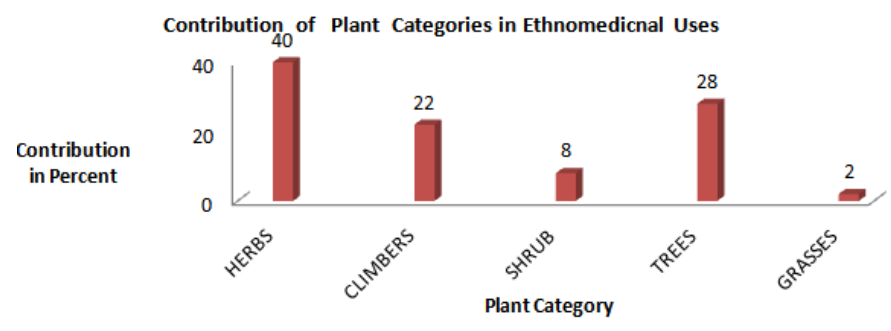

Figure 2 Contribution of plant categories in ethnomedicnal uses.

\section{Interview with informants of knowledge}

The informants were asked about ethno- botanical uses from 11 vaidraj and 23 other respondents ( tribal's) for verification of prescription who were inhabitat in six clusters of villages Batkakhapa, Chhind, Haarai, Junardeo, Patalkot and Rated in Chhindwara district.

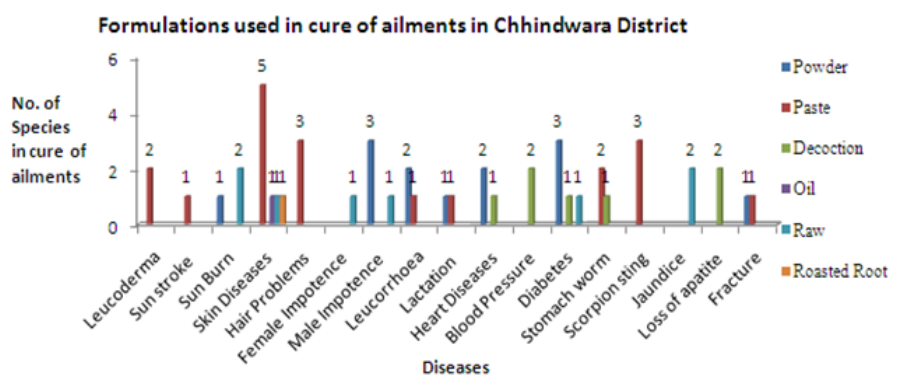

Figure 3 Use of formulations in cure of various ailments in Chhindwara district.

\section{Contribution of Plant Parts in Ethnomedinal uses}

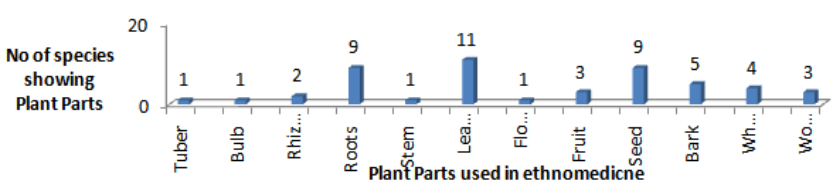

Figure 4 Showing contribution of plant parts in ethnomedicne.

During the visits a rapport was made with number of elderly person of tribal communities as well as traditional herbal healers, who were contacted to collect the information and interviewed. The information documented for 50 prescription as presented in Table 1 from local vaidraj, traditional healers regarding the ethno-botanical data (Local name of plant, Family, plant part used, formulation in medicine in cure of various ailments) and were recorded for descriptive response. ${ }^{22}$ The discussion revealed local name of species, plant part used, formulation of herbal drug used by traditional healers and tribal communities. The specimens were collected, processed and identified with help of flora. The specimens were collected, processed and identified with help of flora. The information recorded in field were further screened in laboratory as per work pertaining to Indian ethno-botany and plants recorded. ${ }^{23-29}$ The information as genus of plant species, local name, family, plant part used of plant species, formulation in cure of ailments prevalent among tribal community have been tabulated in the present investigation in Table 1.

\section{Data analysis}

Interviews and group discussions were conducted to gather information on plant uses, parts used, and modes of utilization. A checklist was developed and used to determine what species were used to treat what kinds of diseases/disorders. Special attention was paid to record information from local vaidys, ojha and traditional herbal healers.

\section{Results and discussion}

In the present investigation, 50 plant species belonging to 27 families under 41 genera were documented which were being traditionally used in six cited clusters in Chhindwara districts. The herbal remedies are effective against 20 ailments such as Leucoderma, sun-stroke, skin burn, skin disease, boils, baldness and hair problems, male and female impotency, leucorrhoea, lactation, heart ailments, blood pressure, diabetes, intestinal worms, scorpion sting, snake-bite, jaundice, fracture and loss of appetite. Among the prevalent plant species maximum plant contribution was recorded in six cluster of villages for herbs with 20 species $(40 \%)$, followed by trees with 14 species $(28 \%)$, climbers with 11 species $(22 \%)$, shrubs with 4 species $(8 \%)$ and grasses with 1 species $(2 \%)$ as shown in Figure 2. The 
formulation being used by 50 species were grouped into formulation used with number of species such as powder, paste, decoction, oil, raw, roasted etc. as shown in Figure 3. The contribution of plant parts of the 50 preferred species was maximum for leaves with 11 species $(22 \%)$, followed by use of seeds of 9 species $(18 \%)$ as well as roots with 9 species (18\%), followed by use of bark with 5 species $(10 \%)$, followed by use of whole plant (Panchang) with 4 species $(8 \%)$, followed by use of fruits with 03 species $(6 \%)$, as well as use of wood with 03 species ( $6 \%$ ), followed by use of rhizome with 2 species $(4 \%)$, followed by use of bulb, flower, tuber and stem with 1 species each of four parts (2\%) of their contribution as shown in Figure 4.

The information recorded during survey revealed that tribal and other local inhabitants had sound knowledge about the uses of medicinal plants in different clusters in Chhindwara district in Satpura plateau. The documented information from local vaidraj were verified from local inhabitants. The tribal medicine -men who were knowledge person, has lot of exposure on plants occurring in and around their clusters in forest localities, even had knowledge on pharmaceutical and therapeutic values, safety measure, doses, as recorded.

The household remedies practiced by the rural communities through trial and error method are not only accurate but also confirm to the Ayurvedic system. The major challenge today is to protect this traditional knowledge as no written document is available and the knowledge has survived only by word of mouth from generation to generation. Due to indiscriminate exploitation, destruction of forests and changing scenario of rural life style, the oral folklore of plants as well as the knowledge is in the process of degeneration. The household remedies practiced by the rural communities through trial and error method are not only accurate but also confirm to the Ayurvedic system. The major challenge today is to protect this traditional knowledge as no written document is available and the knowledge has survived only by word of mouth from generation to generation. Due to indiscriminate exploitation, destruction of forests and changing scenario of rural life style, the oral folklore of plants as well as the knowledge is in the process of degeneration.

About $64 \%$ of the total global population remains dependent on traditional medicines for their health care system $^{28}$ whereas about $85 \%$ of the rural population of India depends on wild varieties of plants for the treatment of various diseases from which they suffer were cured..$^{29,30}$ These traditional healers have specialized skill and knowledge as time of collection of different plant parts, preparing formulations from plant parts and dose of administration even without having any formal education. ${ }^{31}$ Herbal drugs obtained from plants are supposed to be much safer, this has been proved in the treatments in cure of various ailments amongst ethnic groups. ${ }^{32}$

\section{Conclusion}

The Indian medicinal plant posses tremendous therapeutic potential as indicated in the various citation against various formulations used in cure of ailments. The plants used for various therapies are readily available, are easy to transport, and have a relatively long shelf life. The most important advantage of herbal medicine is the minimal side effects, and relatively low cost compared to the synthetic medicines. The success of medicinal plants sector mainly depends on the awareness and interest of the ethnic community. It is clear that local people have great expertise with the plants of their environment. The communication is oral and hence due to change in life style of local inhabitants it is necessary to document in systematic manner before such information is lost.

\section{Acknowledgements}

The author acknowledges thanks to local inhabitant in cluster of villages, ethnic community and respondents. The author is thankful to Dr U. Prakasham IFS, Director TFRI for providing various facilities from organization for conducting the studies. The author further acknowledges Director General M.P. Council of Science and Technology, Bhopal for financial assistance in conducting the study.

\section{Conflict of interest}

Author declares that there is no conflict of interest.

\section{References}

1. Gadgil M, Berkest F, Folke C. Indigenous knowledge for biodiversity conservation. Ambio. 1993;22(2-3):151-156.

2. Kala CP. Etnmomedicnal botany of the Apatani in the Eastern Himalaya region of India. J Ethnobiol Ethnomed. 2005;1:11.

3. Bhalla NP, Sahu TR, Mishra GP, et al. Traditional plant medicines of Sagar. M.P. Journal Econ Tax Bot. 1982;3:23-32.

4. Dwivedi SN, Singh H.Ethnobotany of Kols of Rewa Divison M.P. Proc Natl Sen Envir EPCO II. 1984:37-44.

5. Jain SK. Studies on Indian Ethnobotany. Plants used in medicine by tribals of M.P. Bull. Reg. Res. Lab. Jammu. 1962;1(2):126-129.

6. Jain SK. Observation on Ethnobotany of tribals of M.P. Vanyajati. 1963;11(4):177-187.

7. Jain AK, Virale GM, Singh R. Folklore claims on some medicinal plants used by Bheel tribes of Guna district Madhya Pradesh. Indian Journal of Traditional knowledge. 2010;9(1):105-107.

8. Kadel C, WaghVV, Jain AK. Some Ethnomedicinal plants of Jhabua district, Madhya Pradesh. Indian Journal of Traditional Knowledge. 2011;10(3):538-540

9. Patel P, Mahajan SK. A note on medico ethnobotany of Vijagharh (Khargone) Madhya Pradesh. Bulletin of the Botanical Survey of India. 2004;46(1-4):398-402.

10. Jadhav D, Rawat SS. Ethnomedicinal plants used in treatment of various ailments by Bhilala tribe of Alirajpur district Madhya Pradesh. J Econ Taxon Bot. 2011;3(5):654-657.

11. Rakesh K, Srivastava PN, Manju J, Ethnobotanical study of Traditional Medicinal plants used by tribes of Guna district. International Journal of Current Microbiology and Applied Sciences. 2015;4(7):466-471.

12. Rai R, Nath V, Shukla PK. Characteristics and Ethnobotanical studies on Primitive tribes of Madhya Pradesh. In: Recent progress in Medicinal Plants, 'Ethno- medicine and Pharmacognosy' edited. New Delhi: Govils, Publisher: Researcho Book Centre; 2004;8(37):543-552.

13. Rai Rajiv. Indigenous ad Herbal Medicines Prevalent among Tribal Communities in Madhya Pradesh. Journal of Non-Timber Forest Products. 2008;15(3):183-191

14. Jain AK, Virale MG. Some Threatened Angiosperm Taxa of Chambal Eco-region. Phytotaxonomy. 2007;7:107-110.

15. Jain AK. Tribal clans in Central India and their role in conservation. Environmental Conservation. 1998;15(1):368.

16. Jain SP, Singh SC, Srivastava S, et al. Hitherto unreported ethnomedicinal uses of plants of Betul District of Madhya Pradesh. Indian Journal of Traditional Knowledge. 2010;9(3):522-525.

17. Jain AK, Wagh VV, Kadel C. Some ethno-medicinal plants species of Jhabua district, Madhya Pradesh. Indian Journal of Traditional Knowledge. 2011;10(3):538-540. 
18. Jayson EA. An ecological survey at Satpura National Park, Pachmarhi and Bori sanctuaries, Madhya Pradesh. Indian Journal of Forestry. 1991;13(4):288-294.

19. Kala CP. Home gardens and management of key species in the Pachmarhi Biosphere Reserve of India. J Biodiversity. 2010;1(2):111-117.

20. Maheshwari JK. Ethnobotanical documentation of primitive tribes of Madhya Pradesh. J Eco Taxon Bot Additional series. 1996;12:206-213.

21. Mahajan SK. Traditional herbal remedies among the tribes of Bijagarh of West Nimar district, Madhya Pradesh. Indian Journal of Traditional Knowledge. 2007;6(2):375-377.

22. Chopra RN, Chopara SL, Chopra IC. Glossary of Indian Medicinal Plants. 2nd ed. CSIR, New Delhi, India; 1965.

23. Jain SK. Glimpse of Indian Ethnobotany. New Delhi: Oxford and I.B.H Pub; 1981.

24. Jain SK. Dictionary of Indian Folk Medicines and Ethnobotany. New Delhi: Deep Publications; 1991.

25. Kapur SK. Review on Ethno-medico plants for skin affilications. Indian Drugs. 1990;8(5):210-223.
26. Nadkarni AK. Indian Materia Medica. Popular Prakashan Bombay Vol I\&II. 2nd ed. 1982.

27. Srivastava JL, Jain Seema, Dubey Abhlasha. Ethno - medicine for anti- fertility used by tribals in Bastar district of Madhya Pradesh. In Ethnobotany and Medicinal Plants of Indian Sub-continent. Jodhpur: Scientific Publisher; 2000. p. 97-300.

28. Farnsworth NR. Ethno-pharmacology and drug development. In: Ethnobotany and search for New Drugs. Chadwick D J and March U, Ciba Foundation Symposium 183. Chichester, England: Wiley; 1994. $42 \mathrm{p}$.

29. Jain SK. Ethnopharmacology and drug development. In: Ethnobotany and search for New Drugs. Chadwick D J and March U, Ciba Foundation Symposium 183. Chichester: Wiley; 1994.

30. Shukla PK. Role of Research in sustainable and profitable management of NWFP. Vaniki Sandesh. 2004;28(2-3):1-4.

31. Balasubramanium AV, Radhika M. Local health traditions an Introduction. Chennai: Lok Swastha Parampara SamvardhanSamiti; 1981.

32. Mathew KM. An Excursion of flora oF Central Tamil Nadu. New Delhi: Oxford and IBH Publishing Co Pvt Ltd; 1991. p. 641-647. 